\title{
A Personalidade Autoritária e a Teoria da Propaganda Fascista nas Reflexões de Theodor Adorno: Uma Leitura Aproximativa ${ }^{1}$
}

\author{
Luis Mauro Sá Martino \\ Mestre (2001) e Doutor (2004) \\ em Ciências Sociais pela Pontifícia \\ Universidade Católica de São Paulo. \\ Foi pesquisador-bolsista na School of \\ Political, Social and International Studies \\ na University of East Anglia, na Inglaterra \\ (2008-2009). Professor do Programa \\ de Pós-Graduação em Comunicação \\ da Cásper Líbero, onde leciona na \\ Graduação em Jornalismo e é co-editor \\ da Revista Líbero. \\ E-mail: Imsamartino@gmail.com
}

\section{Ângela Cristina Salgueiro Marques \\ Professora do Programa de}

Pós-Graduação em Comunicação Social da Universidade Federal de Minas Gerais. Mestre e Doutora em Comunicação. É co-autora dos livros Diálogose Dissidências: Foucault e Rancière (Appris, 2018 - com Marco Aurélio Prado); e Ética, Mídia e Comunicação (Summus, 2018 - com Luis Mauro Sá Martino). É tradutora das seguintes obras do filósofo Jacques Rancière: $O$ trabalho das Imagens (Chão da Feira, 2021) e $O$ método da cena (Quixote + Do, 2021). E-mail: angelasalgueiro@gmail.com

\footnotetext{
${ }^{1} \mathrm{~A}$ realização deste trabalho contou com o apoio da Coordenação de Aperfeiçoamento de Pessoal de Nível Superior (CAPES) e do Conselho Nacional de Desenvolvimento Científico e Tecnológico (CNPq). Os autores são gratos às professoras Maria Helena Weber e Mariângela Haswani e ao professor Rudimar Baldissera pelos ótimos comentários feitos à primeira versão deste artigo.
}

Resumo: Entre 1946 e 1951, Theodor Adorno, tanto sozinho quanto com colegas, escreveu dois artigos seminais sobre a propaganda fascista, ao mesmo tempo em que trabalhava em uma ampla pesquisa empírica que apareceria, em 1950, com o nome de A personalidade autoritária. Este artigo propõe uma leitura aproximativa dessas obras no sentido de delinear três principais aspectos: 1 . algumas das características de visão a respeito da propaganda fascista; 2 . as condições em que alguém estaria mais propenso a aceitá-la; e 3. como os artigos sobre propaganda e o estudo empírico permitem esboçar um quadro mais amplo das ideias de Adorno sobre mídia, para além da noção conhecida de "indústria cultural", e mostram uma preocupação mais profunda do filósofo com as características do público e a importância política da comunicação.

Palavras-chave: Adorno, mídia, personalidade autoritária, propaganda fascista, política.

La Personalidad Autoritaria y la Teoría de la Propaganda Fascista en las Reflexiones de Theodor Adorno: Una Lectura Aproximada

Resumen: Entre 1946 y 1951, Theodor Adorno escribió, tanto solo como con colegas, dos artículos seminales sobre propaganda fascista mientras trabajaba en una amplia investigación empírica que aparecería en 1950 titulada La personalidad autoritaria. Este artículo propone realizar una lectura aproximada de estos trabajos con el fin de delinear tres aspectos principales : 1 . algunas de las características de la visión sobre la propaganda fascista; 2 . las condiciones bajo las cuales alguien estaría más dispuesto a aceptarla; y 3 . cómo los artículos sobre publicidad y el estudio empírico permiten esbozar un panorama más amplio de las ideas de Adorno sobre los medios, además de la conocida noción de "industria cultural", y muestran un preocupación más profunda por las características del público y la importancia política de la comunicación.

Palabras clave: Adorno, medios de comunicación, personalidad autoritaria, propaganda fascista, política.

The Authoritarian Personality and the Theory of Fascist Propaganda in Theodor Adorno's Reflections: An Approximate Reading

Abstract: Between 1946 and 1951, Theodor Adorno, both by himself and with colleagues, penned a couple of seminal papers on fascist propaganda, while also working on the empirically driven research that would appear in 1950 under the name The authoritarian personality. This article offers an approximative reading of these works to provide an overview of three main aspects: 1 . some characteristics of his concept of fascist propaganda; 2. the conditions under which someone would be more prone to accept it; 3 . how these studies about propaganda and the empirical study sketch a broader account of Adorno's ideas on media beyond the established notion of "culture industry", and show a deeper preoccupation of the philosopher with the media audience characteristics and the political importance of communication. 


\section{Introdução}

Em novembro de 1941, Theodor W. Adorno chegou a Los Angeles, na Califórnia, nominalmente para continuar suas atividades no Instituto de Pesquisa Social. O filósofo, fugindo da perseguição nazista, havia deixado a Alemanha em 1934. Após uma temporada na Inglaterra e na Universidade de Colúmbia, em Nova Yorkonde havia trabalhado em uma pesquisa sobre música no rádio-, Adorno chegava em Los Angeles para realizar aquele que seria seu projeto mais ambicioso: um vasto estudo sobre o preconceito, iniciado na Universidade de Berkeley, em 1944, e publicado, em 1950, com o título de A personalidade autoritária (Jay, 1978; 2018; Wieggerhaus, 2000). O livro, escrito em parceria com Else Frenkel-Brunswik, Daniel Levinson e Nevitt Sanford, contém quase mil páginas. Com ele, Adorno tinha o intuito de evidenciar a "conexão entre as manifestações individuais de preconceito e as determinações sociais e culturais que incitam os sujeitos preconceituosos" (Costa, 2021, p. 347).

Em plena Segunda Guerra Mundial, o preconceito era o fundamento do regime nazista e o ódio racista havia se transformado em política de Estado. Assim, o estudo conduzido por Adorno tinha como objetivo responder duas perguntas principais: como o nazismo foi possível? Ele poderia se repetir?

A primeira pergunta estava relacionada aos anos de formação de Adorno na Alemanha dos anos 1920. Os anos após a Primeira Guerra Mundial, terminada em 1918, pareciam apontar para uma renovação da arte, da política e dos modos de viver. O fim do Império Alemão e a Proclamação da República apontavam para uma era de democracia e liberdade, cujos efeitos logo puderam ser vistos na cultura.

No cinema, por exemplo, foi a época de filmes consagrados como Nosferatu, de F. W. Murnau, e Metrópolis, de Fritz Lang, representantes do chamado expressionismo alemão. Já a indústria musical foi palco de toda a revolução da vanguarda, com nomes como Arnold Schoenberg, Anton von Webern e Alban Berg, de quem Adorno foi aluno de composição. Ademais, os ecos da Revolução Russa se faziam ver e ouvir no cinema de Sergei Eisenstein e na poesia de Maiakóvski, enquanto a literatura de Franz Kafka levava a escrita a novos limites.

À primeira vista, não havia, nos anos 1920, nenhum sinal ou indício da tragédia que iria se abater na década seguinte não só sobre o país, mas também sobre todo o mundo. A democracia parecia consolidada, a economia dava sinais de alguma recuperação e a produção cultural se desenvolvia com uma liberdade inédita - embora, como recorda Kracauer (2019) em seu clássico estudo From Caligari to Hitler, os sintomas já estivessem presentes para quem estivesse em condição de fazer uma leitura.

Como, em menos de dez anos, esse cenário desapareceu? O que levou a população a deixar tudo isso de lado e apoiar o regime nazista? Por que isso aconteceu? A questão é complicada de ser respondida por uma razão: o nazismo havia chegado ao poder pela via eleitoral. O discurso autoritário, exibido sem meias palavras ou qualquer constrangimento, havia convencido uma parte considerável do eleitorado. O que havia, então, tornado as pessoas, de repente, tão receptivas a esse discurso?

Por que pessoas ditas "normais", aparentemente sem nenhum tipo de preconceito ou ódio declarado, de repente se engajavam ativamente em um regime pautado na discriminação e na perseguição às minorias? Até tomar o poder, em 1933, o partido nazista era apenas mais um entre outros - sua propaganda era forte, sem dúvidas, mas a população alemã não precisava ter dado ouvidos a ela.

A segunda pergunta - o nazismo pode se repetir? - é decorrente de outra: o que aconteceu na Alemanha poderia se repetir em outros países? Afinal, se em menos de dez anos um país democrático se tornou uma ditadura fascista, outros países não corriam o mesmo risco? Para Adorno e seus colaboradores, a questão tinha endereço certo: se a Alemanha dos anos 1920 havia se tornado nazista, havia o risco de os Estados Unidos seguirem pelo mesmo caminho? 
Essas questões parecem ter se tornado não apenas contemporâneas, mas também se ampliado em escala mundial, principalmente quando se leva em consideração que algumas das manifestações políticas contemporâneas, de setores tanto da sociedade quanto do campo político, afastam-se de noções consagradas, como democracia e liberdade, quando não há perspectiva de maior justiça e equidade social.

A resposta para essas questões, tanto as mais prementes durante a Segunda Guerra Mundial quanto as formuladas nos anos pós-guerra, foi esboçada por Adorno em dois estudos consagrados exclusivamente à propaganda: Antissemitismo e propaganda fascista (2015a), de 1944, e A teoria freudiana e o padrão da propaganda fascista (2015b), de 1951. Ao mesmo tempo em que escrevia esses textos, Adorno coordenava uma equipe de pesquisadoras e pesquisadores na Universidade de Berkeley em um estudo sobre antissemitismo e preconceito.

Embora o primeiro texto seja mais "teórico" e o segundo eminentemente mais "empírico", o conjunto compartilha alguns pontos em comum no sentido de compreender a comunicação como um processo relativo não apenas à mídia, mas também aos aspectos sociais e psicológicos mais elaborados. Em particular, a recusa de uma "psicologia das massas", como consagrada até então nos estudos de Le Bon (2018), e a busca por um entendimento mais profundo do processo, tomando como base uma elaboração metodológica das concepções de Sigmund Freud em particular, as presentes em Psicologia das massas e análise do eu, de 1921.

Nessa linha de pensamento, este artigo propõe uma leitura aproximativa dessas obras no sentido de delinear três principais aspectos resultantes de nossa revisão: 1. algumas das características de visão a respeito da propaganda fascista; 2. as condições em que alguém estaria mais propenso a aceitá-la; e 3. como, tomados em conjunto, os artigos sobre propaganda e o estudo empírico permitem esboçar um quadro mais amplo das ideias de Adorno sobre mídia, para além da noção conhecida de indústria cultural, e mostram uma preocupação mais profunda do filósofo com as características do público e a importância política da comunicação.

Como recorda Negt (1978), só é possível falar em uma teoria crítica da mídia dentro da perspectiva de uma teoria crítica da sociedade, a partir da qual é possível construir panoramas mais amplos da realidade concreta e realizar a teoria crítica da mídia como um projeto de pesquisa na dialética dos casos particulares.

Wolin (1987) coloca em perspectiva o aspecto propriamente crítico de tal teoria não apenas como uma crítica ao racionalismo, mas também como sua própria negativa. Daí advém um aspecto que não leva ao obscurantismo, mas à revisão da racionalidade dentro de uma perspectiva dialética.

Nos estudos de Comunicação, o conceito de indústria cultural geralmente é acionado como uma espécie de sinônimo de "Escola de Frankfurt" e "teoria crítica", fazendo o todo valer pela parte. Em que pese relativizar essa localização do conceito como parte dos problemas epistemológicos da área, é importante também pensá-lo em articulação com aspectos mais amplos do pensamento crítico, recorda Rüdiger (1998). Dessa maneira, perceber o lugar de $A$ personalidade autoritária dentro desse programa crítico permite não só reconhecer a sua importância, mas também rever a perspectiva do conceito de indústria cultural e o aspecto negativo atribuído à mídia e à comunicação. Ademais, considerar a obra de Adorno nesse contexto, como recorda Leiss (1974), é realizar uma espécie de projeto tardio de emancipação social.

Gomide e Maciel (2015) questionam qual a razão, diante de um conceito que representa tanta potência e atualidade, de uma certa escassez de estudos sobre o tema. De fato, as apropriações empíricas e críticas parecem se estender em um período de várias décadas, mas de maneira rarefeita. Isso, contudo, não acontece apenas no Brasil: é sintomático que alguns estudos sobre o pensamento de Adorno não se dediquem à compreensão dessa obra; por exemplo, nos artigos de revisão bibliográfica de Connell (2000) ou Kalyvas (2004), o tema está ausente. Vale, por isso, pontuar alguns desses trabalhos. 
Em meados dos anos 1970, Teixeira e Polo (1975), a partir da psicologia, já apresentavam uma leitura crítica da obra do filósofo, concentrando sua análise em torno das categorias "autoritarismo" e "personalidade" e questionando a possibilidade de mudança de atitude. Os estudos, no entanto, parecem ter permanecido mais ou menos esporádicos, sem apresentar a pluralidade e as ramificações de outros conceitos associados à Escola de Frankfurt. A dificuldade de acesso à obra pode ter sido um desses fatores, uma vez que ela foi publicada em português apenas em 2019 e exemplares do original em inglês, mesmo em bibliotecas universitárias, é reduzido.

Já mais recentemente, Vilela, Carvalho Neto e Lopes (2010) desenvolveram uma pesquisa empírica na área de Administração a respeito do autoritarismo nas organizações, tomando como base de estudos a Escala $\mathrm{F}$ e alguns dos postulados de A personalidade autoritária. Por sua vez, Crochik (2017) fez um trabalho crítico em que examina a noção de personalidade autoritária a partir de diversos estudos anteriores sobre os preconceitos espalhados pela sociedade. Já Silva (2019) estuda as ressonâncias do autoritarismo em sala de aula, destacando seus aspectos não apenas em relações pedagógicas, mas também relações pessoais e psicológicas.

Dedicadas exclusivamente ao tema, as detalhadas análises de Haber (2014), Antunes (2012) e Costa (2019) - que também assina a introdução da edição brasileira da obra de Adorno - se destacam não apenas pelo seu rigor de leitura, mas também pela articulação que fazem em suas variadas ramificações com as pesquisas realizadas pelos membros da Escola de Frankfurt ligados, direta ou indiretamente, ao projeto. Ambas as análises também destacam as críticas e os problemas de estudar o tema em seu contexto histórico. Logo, para um estudo mais nuançado dessas ligações, remete-se à leitura dessas obras, enquanto uma análise do contexto imediato da produção da obra pode ser visto em Gonçalves e Loureiro (2019).

Nesse sentido, este texto se organiza em duas partes: a primeira apresenta a noção de personalidade autoritária e de Escala $F$, entendidas como indicadores de uma predisposição a aceitar mensagens autoritárias. A predisposição, no entanto, não é automática; ela está ligada a uma série de características e estratégias da propaganda que, se ausentes, a mensagem política não encontra ressonância nas predisposições de certa parte do público. Isso nos leva à segunda parte deste artigo, que delineia esses aspectos, indicados de maneira assistemática por Adorno.

Não existe, porém, a pretensão de ineditismo na exploração dessa trilha. Ao contrário, menciona-se particularmente sobre essa intersecção os trabalhos de Carone (2002; 2012) e Torre (2020). Em diálogo com esses textos, busca-se uma leitura que aproxime os dois aspectos dos textos de Adorno, escritos com cerca de cinco anos de intervalo e fundamentais para a compreensão de certos aspectos da realidade política contemporânea.

\section{O autoritarismo latente e a predisposição ao autoritarismo}

As perguntas gerais na origem desses estudos eram relativamente simples de serem compreendidas: qual a chance de uma pessoa ser receptiva à propaganda fascista? O que torna alguém mais suscetível de ser convencido por um discurso autoritário? Para responder a essas questões, Adorno e o grupo da Universidade de Berkeley desenvolveram uma complexa metodologia que incluiu a aplicação de 2.099 questionários e mais de uma dezena de entrevistas em profundidade com pessoas de várias faixas etárias, classes sociais e conviç̧ões políticas. Carone (2012), logo no início de seu artigo sobre o tema, recorda que o estudo de Adorno não se refere ao "fascismo de Estado" como um fenômeno histórico, mas aos "traços fascistas" ou à "mentalidade fascista", isto é, ao aspecto propriamente subjetivo dessa perspectiva, localizável mesmo dentro de um Estado democrático e capitalista. O estudo evidenciou que:

. . . a formulação de ideologias preconceituosas é produzida por forças sociais objetivas vinculadas ao desenvolvimento do capitalismo, não sendo, portanto, originárias da psique individual. Ao mesmo tempo, contudo, o preconceito não é diretamente derivado de fatores econômicos. A relação entre a determinação social e a inconsciência individual ocorre muito mais como uma formação de compromisso. (Adorno \& Costa, 2021, p. 348) 
Durante o processo, Adorno sabia que não encontraria respostas abertamente fascistas ou autoritárias na resposta aos questionários - afinal, os Estados Unidos estavam justamente lutando contra o totalitarismo. Por isso, junto com seus colaboradores, ele desenvolveu uma série de questionários em que as pessoas deviam dizer se concordavam ou não com frases de conteúdo político indireto:

Uma das maiores descobertas do presente estudo é a de que indivíduos que apresentam extrema suscetibilidade à propaganda fascista tem muito em comum (eles exibem numerosas características que juntas formam uma "síndrome", embora variações típicas no interior desse padrão maior possam ser distinguidas. Os indivíduos que estão no extremo oposto são muito mais diversos. (Adorno, 2019, p. 72)

Por exemplo, seria difícil alguém responder à pergunta "você tem preconceito contra o grupo $x$ ?" dizendo abertamente "sim, tenho" e indicando, em seguida, qual atitude deve ser tomada a respeito. Uma vez que em uma sociedade democrática os direitos e as garantias individuais são assegurados pelo Estado, esse tipo de resposta não seria possível.

No entanto, podemos ver esse preconceito em afirmações indiretas, por meio do uso de frases como "não tenho nada contra, só não quero ser obrigado a conviver com essa gente" ou "nada contra, só acho estranho". Por isso, na elaboração do questionário, os pesquisadores de Berkeley optaram por ver o quanto os entrevistados concordavam com frases desse tipo, em vez de usarem perguntas diretas.

Aos poucos, Adorno e sua equipe começaram a perceber traços de personalidade comuns entre as pessoas que manifestavam essas tendências de respostas e que, por isso, estariam mais abertas a apoiar um discurso fascista. Algumas pessoas que diziam defender valores democráticos mostravam preferências altamente autoritárias nas respostas ao questionário ou nas entrevistas.

Em vez de olhar para o discurso abertamente fascista, Adorno e sua equipe preferiram observar as tendências autoritárias inconscientes, escondidas e adormecidas em um regime democrático, mas que poderiam vir à tona com toda força em um ambiente político favorável e com a colaboração de uma propaganda adequada, isto é, que soubesse tocar nesses pontos.

Vale destacar o quanto Adorno (2008) expressa grande preocupação com a desumanização dos sujeitos quando estes são tratados como instrumentos ou objetos, sem poderem alcançar condições favoráveis à sua emancipação. $O$ intuito de identificar e problematizar as patologias sociais é, como aparece nos escritos, indicar como os oprimidos são destituídos de sua dignidade. Adorno faz isso, sobretudo, em sua abordagem das vidas danificadas pela injustiça; para ele, o alheamento e a negação da singularidade dos sujeitos implicam a negação de sua humanidade e sua captura em um arranjo hierárquico em que "a injustiça extrema torna-se ilusão de justiça, a desqualificação dos homens converte-se em sua igualdade" (Adorno, 2008, p. 190).

É assim que se dá o empobrecimento da relação com outras pessoas: atrofia-se a capacidade de perceber a outra pessoa como tal e não como função da própria vontade; sobretudo, atrofia-se a capacidade de contradição fecunda, de transcender-se a si próprio ao se incorporar o contraditor. Ela é substituída pelo conhecimento julgador dos homens, para o qual, ao fim e ao cabo, o melhor é o mal menor. Essa maneira de reagir, que é o esquema de toda administração e "política de pessoal", desde logo tende ao fascismo. ... Pertence ao elenco básico da dominação, remeter ao campo dos inimigos, todo aquele que se identifica como diferente. (Adorno, 2008, p. 128)

Adorno se preocupa em realizar uma denúncia da objetificação da alteridade e da rigidez individual, derivada do esforço de autoconservação, por meio da criação de um indivíduo reprimido e rígido dentro de uma totalidade não ameaçadora. O diferente é sempre o inimigo e, portanto, a propaganda fascista investe na atenção consciente e concentrada do indivíduo crítico e solitário, que julga e aponta os 
outros como errados, indignos e desprezíveis. Sua crítica à autoconservação e ao retesamento da atenção consciente individual fica ainda mais evidente quando avaliamos os critérios elencados por Adorno para compor os questionários das pesquisas mencionadas.

Assim, a partir de uma longa pesquisa, o grupo de Berkeley chegou a uma conclusão perturbadora: o discurso autoritário não funciona, porque sua propaganda é melhor ou mais convincente. Diante de uma pessoa com tendências democráticas, o discurso não faria o menor efeito, não convenceria a pessoa "de fora para dentro" por meio de algum tipo de persuasão, inculcação, "sugestão" ou "lavagem cerebral". O cenário era muito pior: o discurso autoritário funciona porque encontra ressonância nas tendências autoritárias que existem em estado latente na pessoa.

Carone (2002, p. 196, grifo do autor) destaca que:

... os autores se puseram a descobrir os rastros de conteúdos latentes nos conteúdos manifestos das elocuções. Essa é a razão pela qual na análise são frequentemente utilizados conceitos como projeção, racionalização, paranoia, masoquismo, sadismo, desejo de destruição ou destrutividade, idealização.

É importante destacar a maneira como, por exemplo, as noções de projeção e idealização se articulam de modo a configurar expectativas sobre as ações do líder e suas performances políticas. A construção discursiva do líder pode mobilizar um mecanismo de espelhamento dos anseios populares embasado na mitificação de sua figura e no reforço de símbolos de poder. Tal construção pode tanto reproduzir a perversidade de um líder egocêntrico quanto reafirmar performances destrutivas dos ideais democráticos. A conquista das massas pela personalidade autoritária é geralmente amparada por mecanismos catárticos que desencadeiam uma política de ódio que transparece nos conflitos discursivos em espaços públicos, marcados por uma espécie de incivilidade ligada à expressão de frames de desvalorização, enquadramentos interpretativos desdenhosos e negação de reconhecimento. A falta de reconhecimento, resultado dos enquadramentos autoritários e da intolerância, leva a traumas psicológicos e sociais, sofrimento e autodepreciação. Assim, o conjunto de histórias, argumentos e termos que são usados para produzir hostilidade e contextos totalitários apoia estilos de vida considerados moralmente dignos e critica veementemente aqueles que são amplamente percebidos e considerados desprezíveis. Segundo Fassin et al. (2015), as economias morais, enfatizadas por esse mecanismo que se alimenta da racionalidade dos afetos catárticos, produzem valores e afetos que sustentam julgamentos e sentimentos que estão na base de um senso comum amplamente partilhado. Para o autor, é importante perceber que os regimes totalitários mobilizam, ao mesmo tempo, uma racionalidade ritualística e dramática e uma irracionalidade do consumo que não se faz por apropriação, mas por mimetização e idolatria.

\section{A Escala F}

A predisposição de alguém para aceitar a propaganda fascista está ligada não apenas a uma questão política, mas também a uma série de outras crenças e atitudes da pessoa. Longe de ser um ponto isolado, o fascismo era parte das atitudes de uma pessoa em sua relação com vários outros aspectos de sua vida. Não se tratava de uma preferência ideológica localizada, mas de todo o seu caráter, daí o nome do estudo ser A personalidade autoritária. A pessoa mais aberta aos argumentos da propaganda fascista também demonstrava uma série de outras características autoritárias, tanto em sua visão da realidade quanto em suas perspectivas políticas.

Tal constatação levou os pesquisadores a formularem uma escala de atitudes que se mostraram típicas de quem demonstrava ter traços autoritários. Essa pauta, denominada Escala F - " $f$ " de fascismo -, permitiu aos pesquisadores observar a presença e a intensidade de determinados pontos de vista a respeito da realidade. Os participantes da pesquisa eram apresentados a uma série de frases aparentemente neutras, isto é, não necessariamente políticas, 
mas que indicavam, de maneira indireta, visões ou mais democráticas ou mais autoritárias a respeito da realidade. O grupo de pesquisadores optou por trabalhar com frases que, em seu conteúdo, traziam afirmações de caráter mais autoritário, já que seria improvável perguntar diretamente aos participantes e receber respostas honestas.

Quanto mais a pessoa expressava concordar com a frase, mais pontos fazia na Escala F, e quanto mais alta a pontuação, maiores os traços autoritários indicados. Mas é preciso tomar cuidado com essa afirmação: segundo o próprio Adorno, muitos desses aspectos autoritários eram inconscientes e, portanto, desconhecidos pela própria pessoa. Um indivíduo poderia muito bem revelar esses traços na pesquisa ao mesmo tempo em que, externamente, não apresentaria nenhuma tendência autoritária ou preferência por regimes totalitários.

Isso nos leva a um ponto importante: a Escala F é um indicador do quanto alguém é suscetível a concordar com mensagens autoritárias. Logo, seria paradoxal usar essa escala como uma maneira de rotular alguém de fascista. Ela indica em que medida uma pessoa poderia estar aberta à propaganda, mas não garante, necessariamente, seu apoio, menos ainda uma predisposição determinante. Além disso, a escala não define alguém como autoritário, visto que ninguém está isento de apresentar traços autoritários em seu caráter. Assim, como todo indício, a Escala F deve ser vista e compreendida dentro de um contexto. Destacamos também o fato de que essa pesquisa não avalia o julgamento ético situado dos entrevistados, ou seja, não considera o modo como os quadros de avaliação moral são mobilizados para a tomada prática de decisões éticas e para a composição de um leque possível de escolhas diante de dilemas de justiça. Uma avaliação como essa demanda uma investigação de como, em situações e contextos de ação concretos, as pessoas decidem seus rumos de ação.

Os traços de personalidade de uma pessoa, como recorda Carone (2012), podem ser entendidos, antes de tudo, como "disposições" a uma determinada atitude ou ação, não necessariamente um elemento já presente e desenvolvido. Interpretar o resultado da Escala $\mathrm{F}$ de maneira literal, como uma régua para medir o "autoritarismo" - ou pior, o "fascismo" - dos outros, seria algo na escala de Simão Bacamarte, que diagnostica a loucura alheia até se convencer da própria. Nas palavras de Gomide e Maciel (2015, p. 214):

. . o o sujeito não tem a menor consciência crítica de seu comportamento, pois o que percebe é uma realidade dada, absorvida e devolvida sem transformação, onde não são disponibilizadas as ferramentas necessárias para sua modificação, o que se reflete numa constituição fraca e abalada do Ego.

Os traços autoritários no caráter de alguém orientam as atitudes da pessoa em relação à realidade, isto é, revelam-se em alguns elementos de sua conduta tanto política quanto, e sobretudo, em relação às outras pessoas. O caráter fascista latente, detectado pela equipe de pesquisa, mostrou a fragilidade de um regime democrático que não cultiva a democracia nas relações humanas. Como lembra o cientista político Robert Dahl (2001), situado no lado oposto de Adorno no espectro partidário, uma democracia não pode ser sustentada em bases autoritárias; não adianta falar de democracia como forma de governo para alguém que, em casa e na escola, teve uma educação autoritária. A democracia deve ser ensinada como parte da formação e da construção de valores morais de cooperação no dia a dia. Daí a importância do estudo de Adorno e sua equipe na formulação da Escala F: traços latentes de personalidade podem vir à tona com força e se transformar em ações quando o momento apropriado aparece. A Escala F permite, dessa maneira, compreender o potencial de vínculo com o autoritarismo de uma pessoa a partir das características apresentadas no Quadro 1. 


\begin{tabular}{|c|c|c|}
\hline Item da escala & Definição & Característica \\
\hline Convencionalismo & $\begin{array}{l}\text { Adesão rígida a } \\
\text { valores convencionais. }\end{array}$ & $\begin{array}{l}\text { Preocupação em estar } \\
\text { ajustado aos valores } \\
\text { considerados "normais". }\end{array}$ \\
\hline $\begin{array}{l}\text { Submissão } \\
\text { autoritária }\end{array}$ & $\begin{array}{l}\text { Atitude submissa e acrítica } \\
\text { às autoridades idealizadas } \\
\text { do grupo. }\end{array}$ & $\begin{array}{l}\text { Submissão à autoridade, } \\
\text { desejo de uma liderança } \\
\text { forte e idealização de suas } \\
\text { qualidades ou virtudes. }\end{array}$ \\
\hline $\begin{array}{l}\text { Agressão } \\
\text { autoritária }\end{array}$ & $\begin{array}{l}\text { Tendência a vigiar e } \\
\text { condenar, rejeitar e punir } \\
\text { quem desafia seus valores. }\end{array}$ & $\begin{array}{l}\text { Agressão às pessoas de } \\
\text { fora do seu grupo que não } \\
\text { compartilham suas ideias } \\
\text { e rapidez em condenar } \\
\text { outras pessoas. }\end{array}$ \\
\hline Autointracepção & $\begin{array}{l}\text { Oposição ao subjetivo, ao } \\
\text { imaginativo e a um espírito } \\
\text { compassivo. }\end{array}$ & $\begin{array}{l}\text { Rejeição do } \\
\text { autoconhecimento e pouco } \\
\text { interesse em qualquer coisa } \\
\text { que não seja "prático" ou } \\
\text { "útil" imediatamente. }\end{array}$ \\
\hline $\begin{array}{l}\text { Superstição e } \\
\text { estereotipia }\end{array}$ & $\begin{array}{l}\text { A crença em determinantes } \\
\text { místicos do destino } \\
\text { individual e a disposição } \\
\text { a pensar por meio de } \\
\text { categorias rígidas. }\end{array}$ & $\begin{array}{l}\text { Crença em forças externas } \\
\text { que determinam as ações } \\
\text { humanas e tendência a } \\
\text { pensar em divisões rígidas. }\end{array}$ \\
\hline Poder e "dureza" & $\begin{array}{l}\text { Preocupação com a ideia } \\
\text { de dominação-submissão, } \\
\text { identificação com figuras } \\
\text { de poder e exibição da } \\
\text { força e da dureza. }\end{array}$ & $\begin{array}{l}\text { Exibição constante da } \\
\text { força e do poder e a busca } \\
\text { de proximidade com o } \\
\text { poder ou de atributos que } \\
\text { mostrem isso. }\end{array}$ \\
\hline $\begin{array}{l}\text { Destrutividade e } \\
\text { cinismo }\end{array}$ & $\begin{array}{l}\text { Hostilidade generalizada e } \\
\text { desprezo pelo humano. }\end{array}$ & $\begin{array}{l}\text { Agressividade racionalizada } \\
\text { que se torna "aceitável" } \\
\text { aos olhos da pessoa por } \\
\text { se inserir em uma visão } \\
\text { de mundo. }\end{array}$ \\
\hline Projetividade & $\begin{array}{l}\text { A disposição para acreditar } \\
\text { que coisas tresloucadas } \\
\text { e perigosas acontecem } \\
\text { no mundo e a projeção } \\
\text { para fora de impulsos } \\
\text { emocionais inconscientes. }\end{array}$ & $\begin{array}{l}\text { Tendência a ver nos } \\
\text { outros apenas defeitos e } \\
\text { problemas e a perspectiva } \\
\text { de que "forças do mal" } \\
\text { estão atuando e devem } \\
\text { ser combatidas. }\end{array}$ \\
\hline Sexo & $\begin{array}{l}\text { Preocupação exagerada } \\
\text { com "eventos" sexuais. }\end{array}$ & $\begin{array}{l}\text { Forte interesse na vida } \\
\text { sexual dos outros, sobretudo } \\
\text { em relação às condutas } \\
\text { consideradas "corretas". }\end{array}$ \\
\hline
\end{tabular}

Quadro 1: A Escala F e suas características

Nota: Adaptado de Adorno (2020).

Além desses, a pesquisa mostrou outros dois itens relacionados à personalidade do tipo autoritário, porém em termos de suas atitudes diante da política, no sentido estrito do termo.

Em primeiro lugar, um ponto foi denominado pelos autores do estudo como "ignorância e confusão". Não significa, entretanto, que essas duas características refletem o grau de instrução da pessoa; elas se tratam muito mais de uma atitude diante da realidade do que qualquer outra coisa. Podem também ser interpretadas como a recusa em conhecer outros pontos de vista sobre um assunto, que poderiam mostrar mais lados de uma questão. Assim, uma das características é o apego a 
um determinado ponto de vista, muitas vezes genérico e estereotipado, que deixa de lado as nuances e as complexidades de uma situação.

A opinião pessoal é elevada à categoria de verdade ao mesmo tempo em que a ausência de formação para falar sobre um assunto não é vista como um problema. Dito de outra maneira, todas as opiniões teriam o mesmo valor, independentemente do grau de embasamento. Como consequência, isso coloca todos os pontos de vista no mesmo nível: a opinião de um leigo é considerada equivalente à do especialista, ainda que décadas de estudo separem uma da outra. A validade de uma opinião não depende, neste caso, das credenciais específicas de quem fala-por exemplo, conhecer bem um assunto -, mas do simples fato de ser uma "opinião" como todas as outras.

Nas palavras de Adorno (2019, p. 344):

A avaliação das afirmações políticas contidas em nosso material das entrevistas deve ser considerada em sua relação com a ignorância e a confusão generalizadas de nossos sujeitos em assuntos políticos, um fenômeno que pode muito bem superar o que até mesmo um observador cético poderia ter antecipado. Se as pessoas não sabem do que estão falando, o conceito de "opinião", que é básico para qualquer abordagem da ideologia, perde muito de seu significado.

Consideramos importante pensar criticamente o conceito de opinião mobilizado pelo filósofo. Adorno destaca apenas a necessidade de formular uma opinião informada, visto que, muitas vezes, a opinião é amparada por crenças e quadros valorativos inegociáveis - atrelados ao repúdio de qualquer ponto de vista contrário-, bem como por sistemas de estereótipos que conferem ao sujeito a falsa sensação de poder emitir sua opinião sobre qualquer tema ou problema. Mas a construção de um ponto de vista e de uma atitude política são apenas dimensões de um processo de formação de opinião que é muito mais amplo e complexo, porque requer o debate e a justificação recíproca em redes de esferas públicas democráticas. Assim, apesar de as mensagens mediáticas perpassarem o modo como os cidadãos comuns produzem entendimentos acerca do universo da política, o que faz as pessoas pensarem de determinada forma é uma multiplicidade de tramas discursivas constituídas de diferentes maneiras e em diferentes contextos. Isso revela um trabalho comunicativo e intertextual que não se reconfigura a cada nova informação processada, mas a cada rede interativa mobilizada (Gamson, 1992).

A divulgação de informações falsas nas redes sociais, por exemplo, beneficia-se muito desse tipo de pensamento: a opinião de um leigo a respeito de um assunto pode ser levada mais a sério do que a de alguém preparado para falar do assunto, porque o leigo simplesmente diz o que um grupo ou outra pessoa quer ouvir, com ou sem fundamento. Não se trata de falta de informação, mas, talvez, de seu contrário:

É difícil distinguir entre a simples ignorância e a confusão, quer dizer, entre o estado de simplesmente não conhecer os fatos e o estado que existe quando pessoas sem treinamento intelectual suficiente ficam confusas sob o incessante ataque de todos os tipos de comunicação de massa e propaganda e não sabem o que fazer com os fatos que se apresentam. (Adorno, 2019, p. 346)

A busca por formular um ponto de vista que garanta um mínimo de conforto psicológico diante de um cenário fragmentário, multifacetado e até mesmo incompreensível - e, retomando a advertência de Torre (2020), isso não está ligado ao grau de instrução do indivíduo -, tem como saída o recurso da certeza pronta, disponível para ser erigida em forma de verdade.

Todavia, tal pensamento está fechado não só às opiniões contrárias, mas também a um aprofundamento de qualquer assunto que apresente aspectos mais complicados. Assim, baseando-se em informações genéricas, o indivíduo constrói um conhecimento bastante confuso da realidade, mas suficiente para formar sua opinião a respeito de um assunto: 
Comunicações de massa modernas, moldadas a partir da produção industrial, espalham todo um sistema de estereótipos que, embora ainda sendo fundamentalmente "incompreensível" para o indivíduo, permite que ele pareça a qualquer momento como estando atualizado e "sabendo tudo a respeito". Assim, o pensamento estereotipado em questões políticas é quase inescapável. (Adorno, 2019, p. 358)

Em segundo lugar, o grupo de pesquisa notou uma tendência à personalização da política: no lugar da discussão de ideias ou propostas, aposta-se em uma pessoa "esse aí vai dar um jeito" ou "esse aí resolve" -, em que serão depositadas as esperanças políticas. Nesse cenário, a figura do líder político ganha bastante força: a escolha é pela pessoa, não por um partido ou projeto; as qualidades pessoais ou as ideias do líder são levadas em consideração na escolha política, mas não as possibilidades reais de a pessoa fazer algo.

Consistente com isso é o caráter altamente personalizado da propaganda política, particularmente das campanhas eleitorais, em que as questões objetivas em jogo estão na maioria das vezes ocultas por detrás da exaltação dos indivíduos envolvidos, frequentemente em categorias que pouco tem a ver com as funções que esses indivíduos deveriam cumprir. (Adorno, 2019, p. 366)

Projeta-se, assim, sobre a pessoa as capacidades e as responsabilidades que, na política, costumam ser divididas em vários níveis. Dessa maneira, cria-se a expectativa de uma solução rápida e definitiva dos problemas que, por sua vez, deve ser obtida simplesmente pela capacidade de ação de uma única pessoa o "salvador da pátria" -, elemento ressaltado pela pessoa em destaque:

Embora realmente reflitam seus ouvintes na maioria dos aspectos, [essas pessoas] diferem deles em um ponto importante: não conhecem inibições ao se exprimir. Eles atuam de forma vicária por seus ouvintes desarticulados ao fazer e dizer o que os últimos gostariam, mas não conseguem ou não se atrevem a tal. Violam os tabus que a sociedade de classe média colocou sobre qualquer comportamento do cidadão normal e realista. (Adorno, 2015, p. 145)

Para que essas tendências de personalidade se transformem em ações por exemplo, o preconceito latente que se torna violência -, vários fatores são necessários. Um deles, no entanto, já vinha chamando a atenção de Adorno há algum tempo: a propaganda.

\section{As características da propaganda fascista}

As preocupações de Adorno eram fundamentadas: alguns anos antes, ele e dois colegas, Leo Löwenthal e Norbert Guterman, haviam feito extensas pesquisas sobre a propaganda política de caráter autoritário nos Estados Unidos. Eles estudaram programas de rádio, revistas e panfletos que, às vezes sob a aparência de defesa da democracia ou da liberdade, tinham um discurso bastante autoritário e contrário às liberdades, direitos e garantias das pessoas. A partir de uma detalhada análise, pautada em um ponto de vista que combinava sociologia crítica e psicanálise, Adorno, Löwenthal e Guterman puderam observar quais eram as estratégias que esses materiais utilizavam para chegar ao público.

O estudo levou Adorno (2015a; 2015b) a fazer uma síntese dos principais métodos da propaganda autoritária, que foram sintetizados em dois artigos: "Antissemitismo e propaganda fascista" e "A teoria freudiana e o padrão da propaganda fascista". Nesses textos, Adorno mostra como a propaganda fascista não estava dirigida apenas à razão ou às expectativas políticas de um público, mas, sobretudo, a uma série de características inconscientes - o que, mais tarde, em A personalidade autoritária, ele identificou como latentes. Torre (2019), contudo, apresenta uma ressalva em relação a esse item:

Uma questão importante: não se trata apenas de manipulação das pessoas sem instrução. Embora isso também ocorra, esse argumento sozinho seria errôneo e de cunho elitista. A propaganda fascista mobiliza forças inconscientes - 
que estão presentes em todos nós, instruídos e não instruídos. É por essa razão que os estudos sobre a personalidade autoritária foram feitos conjuntamente com os estudos sobre a propaganda fascista, com o fito de compreender quais forças essa propaganda visa mobilizar. (Torre, 2019, p. 106)

Como destaca Antunes (2012), o conceito de indústria cultural não está presente em A personalidade autoritária:

. . . ao invés dele, os autores utilizaram os termos genéricos "mídia" e "comunicação de massa", para se referir aos meios com que o clima cultural, amplamente padronizado como os processos industriais - apesar e por conta de suas particularidades que não podem ser negligenciadas -, chega aos sujeitos de um modo também estandardizado, reproduzindo-se neles, alimentando-os com “a pedra da estereotipia”. (Antunes, 2012, p. 196)

Se o poder da propaganda não estava apenas em seu conteúdo, mas também nas predisposições dos indivíduos para aceitar um discurso autoritário, era preciso observar quais eram as características dessa mensagem. Trabalhando a partir das ideias de Freud, Adorno chegou a definir algumas dessas estratégias.

\section{Personalização}

A personalização, uma dessas estratégias, pode ser percebida quando a figura do líder é ressaltada o tempo todo, seja como modelo ideal a ser seguido e, portanto, distante, seja como figura próxima - "gente como a gente". Ainda, o líder pode ser retratado como o porta-voz do grupo que representa, expressando opiniões e ideias que outras pessoas não falariam - "ele fala as verdades que ninguém quer ouvir".

\section{Os meios substituem os fins}

Os objetivos políticos nunca são alcançados, mas estão sempre a um passo de distância: para alcançá-los, é necessário se manter em movimento. Por isso, a propaganda está o tempo todo deslocando a atenção do público para novos objetivos e mostrando que participar do processo é mais importante do que chegar a um resultado.

\section{Imprecisão das propostas e dos raciocínios: a realização do desejo}

Outra estratégia da propaganda autoritária é que ela sempre faz promessas de transformação e mudança para o melhor, mas nunca indica exatamente quais serão essas alterações ou como, na prática, elas serão feitas. No lugar dessas propostas, entra em cena a promessa de uma realidade diferente e melhor e apontar esse futuro se torna uma gratificação em si. Assim, a imprecisão das propostas e dos raciocínios leva à realização do desejo.

\section{Ataque a inimigos imaginários}

A relação de amor e a fidelidade ao grupo ao qual se pertence só podem ser equilibradas por uma relação de ódio a outras pessoas, povos e comunidades. $\mathrm{O}$ ódio ao outro, compartilhado pelos participantes, é um dos elementos necessários para manter a integração, sendo que o amor às pessoas internas ao grupo só parece existir se houver um sentimento de ódio, na mesma proporção, aos indivíduos que não pertencem a ele. Um grupo é escolhido como "inimigo" e a ele é atribuído todas as qualidades negativas, bem como a culpa por todos os problemas. O preconceito, nesse sentido, pode muito bem ser dirigido contra mais de um grupo - os mesmos problemas podem ser atribuídos a vários grupos diferentes. Como recorda Carone (2002, p. 196), "a discriminação enquanto comportamento político fascista estaria muito mais na dependência da psicologia do discriminador do que das características dos alvos da discriminação". 


\section{Ausência de lógica, substituída por um raciocínio por similaridade}

A propaganda autoritária, evidentemente, não se dirige apenas às emoções. Ela também precisa dizer algo ao pensamento e, para isso, precisa ter uma racionalidade. No entanto, os raciocínios apresentados não seguem uma lógica, mas fazem todo tipo de curva e desvio para provar um ponto, mesmo quando isso significa se contradizer. Assim, a ausência de lógica é substituída por um raciocínio por similaridade.

\section{Repetição e estereotipificação}

Os poucos slogans, propostas ou palavras são repetidos à exaustão, ainda que seu significado nem sempre seja bem definido. Um pequeno conjunto de ideias, sintetizadas nesses materiais, é incessantemente repetido, de maneira a ser conhecido e memorizado. Para facilitar essa assimilação, a propaganda autoritária deixa de lado qualquer sutileza ou nuance: o mundo é representado a partir de estereótipos, que são usados para classificar rapidamente pessoas e situações:

A propaganda fascista precisa apenas reproduzir a mentalidade existente para seus próprios propósitos - ela não precisa induzir uma mudança -, e a repetição compulsiva, que é uma de suas características mais importantes, irá se coordenar com a necessidade por sua produção contínua. (Adorno, 2015, p. 184, grifo do autor)

\section{Ritualidade e performance}

Se os rituais e performances são parte integrante da política, na propaganda autoritária eles são os protagonistas. Há uma teatralidade política não só constante, mas também em vários níveis nas atitudes das lideranças, no sentido de reforçar a imagem esperada do movimento. A propaganda, tendo ritualidade e performance, não está limitada a um momento, mas todo o cotidiano se torna uma forma de propaganda. Como lembra Adorno (2019), uma das características do totalitarismo é exatamente não ter limites.

Esses elementos, indica Adorno (20150a; 2015b), tornam a propaganda fascista uma espécie de "show" muito próximo dos produtos da mídia. O autor utiliza como exemplo de gratificação as novelas de rádio: uma pessoa, emocionada com a história narrada, baixa suas barreiras e aceita a publicidade do anunciante com mais facilidade. Esse tipo de mensagem emocional torna o público mais predisposto às ideias políticas.

Como observado em outros estudos (Martino, 2007; 2012), esse tipo de propaganda parece se aproximar, sobretudo, do entretenimento, a partir de uma perspectiva não propriamente de apresentação e debate de ideias políticas. Trata-se, na verdade, de uma forma de ação que privilegia a performance da política e destaca a sua visualidade, trilha largamente seguida pela propaganda democrática, como assinalam, entre outros, Alexander (2010), Martino (2011), Panke (2010), Panke e Philippi (2019), Rees (1997), Rubim (2000) e Weber (2000; 2021).

Há, contudo, uma consequência imediata no campo político, indicada por Adorno (2019): a perda de interesse na política, que, na melhor das hipóteses, será vista como algo distante da vida cotidiana, com a qual o público não manteria nenhuma relação direta, e a percepção da saturação dos mesmos problemas, figuras e situações. A apresentação da política, para Adorno, está diretamente relacionada a isso:

Notícias e comentários políticos, como todas as outras informações veiculadas pelo rádio, imprensa e noticiários são geralmente absorvidos nos momentos de lazer e se encontram, de certa forma, enquadrados como "entretenimento". . . . Visto dentro desse esquema de referência, a política é necessariamente "decepcionante". . . . O despontamento com a política como uma atividade de lazer que não gera retornos rápidos provavelmente produz indiferença, e é bem possível que a ignorância predominante se deva não apenas à falta de 
familiaridade com os fatos, mas também a uma espécie de resistência contra o que deveria servir como passatempo e que em geral tende a ser desagradável. (Adorno, 2019, p. 354)

Não se trata, no entanto, de um "efeito colateral" da comunicação política, mas de uma característica que se desenha paralela às características de personalidade: o desapontamento com o campo político tradicional, incompreensível em seus meandros e, por isso, também em seu alcance, abre caminho para a presença de outsiders que, apresentando-se como externos ao campo político, tomam posição ao lado do cidadão comum a respeito do espaço ao qual busca pertencer.

\section{Considerações finais}

A leitura conjunta dos textos de Adorno sobre a propaganda fascista e a personalidade autoritária mostram um panorama complexo sobre o processo de comunicação, que mesmo nas sociedades democráticas pode se tornar uma forma de acesso ao pensamento autoritário. Em termos do pensamento teórico da comunicação, trata-se, talvez, de uma das poucas vezes em que uma série de premissas sobre propaganda e persuasão tiveram sua compreensão elaborada a partir de uma base freudiana que privilegia aspectos profundos e menos visíveis da personalidade em vez de buscar um "feedback" quantitativo. Isso, embora não delineie uma relação de influência ou causa e efeito - e nem é esse o propósito das pesquisas -, apresenta-se como um fator novo no cenário comunicacional ao apontar elementos novos no processo.

Como se argumenta que a propaganda fascista engana as pessoas fazendo-as acreditar que sua situação irá melhorar, então surge a questão: por que elas são tão facilmente enganadas? Por causa, pode-se supor, de suas estruturas de personalidade; por causa de padrões de expectativas e aspirações, medos e angústias há muito estabelecidos que as dispõem a certas crenças e as tornam resistentes a outras. A tarefa da propaganda fascista, em outras palavras, torna-se mais fácil dependendo do grau em que potenciais antidemocráticos já existem na grande massa de pessoas. (Adorno, 2019, p. 88)

Quando as redes sociais se tornaram populares, nas primeiras décadas do século XXI, houve vários debates a respeito de sua capacidade de influenciar pessoas, de gerar discussões e ações e de se tornar um centro de debate político que poderia, em última instância, mobilizar as pessoas e levar a mudanças reais. Assim, momentos de euforia e desilusão se alternaram à medida que se notava a dificuldade de pensar a noção de "influência", visto que estávamos transpondo para o ambiente das mídias digitais nossas potências e limites como seres humanos tanto para o bem quanto para o mal.

A pergunta se mantinha e as respostas não poderiam ser mais ambíguas. Existem maneiras muito diferentes de engajamento: algumas são mais pontuais e esporádicas, enquanto outras são mais aprofundadas e de longo prazo. Mas não se pode dizer que uma ou outra é mais eficaz ou apropriada, uma vez que muitos movimentos cívicos e sociais têm sua principal forma de ação baseada em ações ocasionais e no engajamento pontual em ações esporádicas.

\section{REFERÊNCIAS}

Adorno, T. W. (2008). Minima moralia. Beco do Azougue.

Adorno, T. W. (2015a). Antissemitismo e propaganda fascista. In T. W. Adorno, Ensaios sobre psicologia social e psicanálise (pp. 137-151). Editora Unesp.

Adorno, T. W. (2015b). A teoria freudiana e o padrão da propaganda fascista. In T. W. Adorno, Ensaios sobre psicologia social e psicanálise (pp. 153-189). Editora Unesp.

Adorno, T. W. (2019). Estudos sobre a personalidade autoritária. Editora Unesp. 
Adorno, T. W., \& Costa, V. H. F. (2021). Observações sobre 'a personalidade autoritária' de Adorno, Frenkel-Brunswik, Levinson e Sanford. TRANS/FORM/AÇÃO, 44(2), 345-384. https://doi.org/10.1590/0101-3173.2021.v44n2.24.p345

Alexander, J. C. (2010). The performance of politics: Obama's victory and the democratic struggle for power. Oxford University Press.

Antunes, D. C. (2012). Por um conhecimento sincero do mundo falso: Teoria crítica, pesquisa social empírica e the authoritarian personality [Tese de doutorado, Universidade Federal de São Carlos]. Repositório Institucional UFSCar.

Carone, I. (2002). Fascismo on the air. Lua Nova: Revista de Cultura e Política, 55-56(1), 195-217. https://doi.org/10.1590/S0102-64452002000100009

Carone, I. (2012). A personalidade autoritária: Estudos frankfurtianos sobre o fascismo. Revista Sociologia em Rede, 2(2), 14-21.

Connell, M. F. (2000). Imagining Adorno: Critical theory under review. Theory, Culture \& Society, 17(2), 133-147.

Costa, V. H. F. (2019). 'A personalidade autoritária': Antropologia crítica e psicanálise [Tese de doutorado, Faculdade de Filosofia, Letras e Ciências Humanas, Universidade de São Paulo]. Dedalus.

Crochik, J. L. (2017). Personalidade autoritária e pesquisa empírica com a Escala F: alguns estudos brasileiros. Impulso, 69(27), 49-64. https://doi.org/10.15600/2236-9767/ impulso.v27n69p49-64

Dahl, R. (2001). Sobre a democracia. Editora UnB.

Fassin, D., Bouagga, Y., Coutant, I., Eideliman, J.-S., Fernandez, F., Fischer, N., Kobelinsky, C., Makaremi, C., Mazouz, S., \& Roux, S. (2015). At the heart of the State: The moral world of institutions. Pluto Press.

Gamson, W. A. (1992). Talking politics. Cambridge University Press.

Gomide, A. P. A., \& Maciel, R. M. (2015). O legado da pesquisa the authoritarian personality para o campo da psicologia social. Perspectivas em Psicologia, 19(1), 196-216.

Gonçalves, E. C., \& Loureiro, R. (2019). Nota sobre os estudos de T. Adorno em Berkeley: A 'farsa da farsa' na América Latina e o vigor da escala F. Problemata: International Journal of Philosophy, 10(4), 227-254. https://doi.org/10.7443/ problemata.v10i4.49660

Haber, S. (2014). Patologias da autoridade: alguns aspectos da noção de "personalidade autoritária" na escola de Frankfurt. Princípios, 21(36), 337-360.

Jay, M. (1978). As ideias de Adorno. Cultrix.

Jay, M. (2018). A imaginação dialética. Contraponto.

Kalyvas, A. (2004). Back to Adorno? Critical social theory between past and future. Political Theory, 32(2), 247-256. https://doi.org/10.1177\%2F0090591703256672

Kracauer, S. (2019). From Caligari to Hitler: A psychological history of the German film. Princeton University Press.

Le Bon, G. (2018). Psicologia das multudões. WMF Martins Fontes.

Leiss, W. (1974). Critical theory and its future. Political Theory, 2(3), 330-349. https://doi.org/10.1177\%2F009059177400200306 
Martino, L. M. S. (2007). A estética da propaganda política em Goebbels. Comunicação \& Política, 25, 35-53.

Martino, L. M. S. (2011). Três hipóteses sobre as relações entre mídia, entretenimento e política. Revista Brasileira de Ciência Política, (6), 137-150. https://doi.org/10.1590/ S0103-33522011000200006

Martino, L. M. S. (2012). Além do paradigma: Propaganda política e democracia em seis artigos de Harold Lasswell. Interin, 13(1), 1-13.

Negt, O. (1978). Mass media: Tools of domination or instruments of liberation? Aspects of the Frankfurt school's communications analysis. New German Critique, (14), 61-80. https://doi.org/10.2307/488061

Panke, L. (2010). Política e entretenimento: Cruzamento e/ou interferência na construção de sentidos. Animus, 9(18), 13-30.

Panke, L., \& Philippi, R. (2019). Entre a comunicação, a política e o espetáculo. Vozes e Diálogo, 18(1), 20-32. https://doi.org/10.14210/vd.v18n01.p20-32

Rees, L. (1997). Vende-se política. Paz e Terra.

Rubim, A. A. C. (2000). Comunicação e Política. Hacker Editores.

Rüdiger, F. (1998). A trajetória da crítica à indústria cultural. Estudos de Sociologia, 4, 17-30.

Silva, P. R. (2019). Personalidade autoritária em sala de aula: Ressentimento e sadismo em tempos de cultura digital [Tese de doutorado, Universidade Federal de São Carlos]. Repositório Institucional UFSCar.

Teixeira, J. B. C., \& Polo, A. (1975). A personalidade autoritária: Componentes e gênese psicológica. Arquivos Brasileiros de Psicologia Aplicada, 27(4), 47-69.

Torre, B. D. (2020). Com quantos paus se faz uma canoa? Notas sobre a personalidade autoritária. Crítica Marxista, 50(1), 103-109.

Vilela, J. R. P. X., Carvalho Neto, A., \& Lopes, H. E. G. (2010). O autoritarismo em cooperativas e empresas privadas: Uma investigação com dirigentes e gerentes por meio de uma escala baseada na escala F de Adorno. Revista de Administração da USP, 45(1), 84-96.

Weber, M. H. (2000). Comunicação e espetáculos da política. Editora UFRGS.

Weber, M. H. (2021). A perversa narrativa presidencial e a comunicação pública. In R. Sampaio, R. Sarmento \& V. Chagas (Orgs.), Comunicação e política no contexto da pandemia: Breves reflexões (v. 1, pp. 31-40). Compolítica.

Wieggerhaus, R. (2000). A escola de Frankfurt. Difel.

Wolin, R. (1987). Critical theory and the dialectic of rationalism. New German Critique, (41), 23-52. 